\title{
A longitudinal study of alveolar bone loss around maxillary central incisors in patients with leprosy in Malaysia
}

\author{
KRISHNAN SUBRAMANIAM*, \\ SEANG HOO NAH* \& SANDY C. MARKS $\dagger$ \\ * Department of Anatomy, Faculty of Medicine, University of \\ Malaya, Kuala Lumpur, Malaysia; and †Department of Cell \\ Biology, University of Massachusetts Medical School, 55 Lake \\ Avenue North, Worcester, MA, USA
}

\section{Accepted for publication 16 December 1993}

Summary The loss of alveolar bone supporting the maxillary central incisors and the general periodontal conditions were evaluated after 14 years in the 12 patients remaining from an original group of 47 under treatment in Malaysia. Alveolar bone loss was minimal during this period even in the presence of periodontal inflammation. These data suggest that treatment protects patients with leprosy from alveolar bone loss and suggests that other skeletal deformities might respond similarly.

\section{Introduction}

Skeletal involvement is a major complication in advanced leprosy $y^{1,2}$ because of the net loss of bone. ${ }^{3}$ Moller-Christensen, in evaluating medieval skulls excavated from a Danish cemetery, first noted and documented a tripartite resorption phenomenon in the maxilla involving the palatine process, alveolar bone supporting the incisor teeth and the anterior nasal spine which he described as facies leprosa. ${ }^{4}$ Contemporary studies on osseous resorption around these sites in the maxilla have confirmed that resorption of the alveolar process of the maxilla is a characteristic feature of the disease. ${ }^{5,6}$ In a study initiated in 1977 on patients under treatment at the National Leprosy Control Centre in Malaysia we demonstrated that loss of alveolar bone was maximal in the maxillary anterior region, that patients with lepromatous leprosy had a greater degree of alveolar bone loss compared to those with borderline or tuberculoid leprosy ${ }^{7}$ and that this resorption of bone was mediated by osteoclasts. ${ }^{8} \mathrm{~A}$ follow-up study on 22 patients (from the original patient pool of 47) 4 years later showed that the rate of alveolar bone loss was minimal in patients with lepromatous, borderline or tuberculoid leprosy ${ }^{9}$ and similar to that seen in larger populations without leprosy. ${ }^{10,11}$

$\ddagger$ Correspondence: S. C. Marks. 
The purpose of the present study was to extend our earlier observations ${ }^{9}$ af ter a lapse of 10 years to determine if the risk of accelerated bone loss observed in untreated lepromatous leprosy ${ }^{12}$ is greatly reduced in patients maintained on treatment, as seen in other skeletal and soft tissue deformities of this disease.

\section{Materials and methods}

The patients still available from the original group ${ }^{7}$ were recruited for this study. All patients up to 1987 were on $50 \mathrm{mg}$ dapsone daily with a supervised monthly dose of $100 \mathrm{mg}$. Multidrug (MDT) therapy was begun at the National Leprosy Control Centre in Malaysia in 1987. Patients with multibacillary disease received a pulse dose of rifampicin $(600 \mathrm{mg})$, clofazimine $(100 \mathrm{mg})$ and dapsone $(100 \mathrm{mg})$ on day 1 followed by clofazimine $(100 \mathrm{mg})$ and dapsone $(50 \mathrm{mg})$ for 27 days. This cycle was repeated for 2 years after which treatment was stopped and patients were followed for up to 4 years. Patients with paucibacillary disease received the same regimen without clofazimine. All patients had received this regimen and showed no evidence of relapse. Written consent was obtained after the procedures were explained to each patient.

Alveolar bone loss in the maxilla was measured radiographically ${ }^{13}$ as described previously ${ }^{7}$ using periapical radiographs taken with the paralleling long-cone technique. $^{14}$ The angle between the plane of the film and the X-ray beam was adjusted to between $50^{\circ}$ and $60^{\circ}$ for each patient because angulations within this range have been shown to have little effect on the calculation of alveolar bone support from multiple assessments. ${ }^{13}$ Radiographs were magnified $10 \times$ and measurements from the root apex to the cemento-enamel junction and to the alveolar crest were made to the nearest $0.05 \mathrm{~mm}$ on each side of the maxillary central incisors using needle callipers and a micrometer. Duplicate measurements differed less than 3\%. The reduction in alveolar bone support (which translates to bone loss) was expressed as a percentage by subtracting the current bone height related to the root length of the maxillary central incisor, from that present initially, which can be presumed to be the full root length, up to the level of the cemento-enamel junction. ${ }^{9}$ The difference in the values between the present data and those obtained in 1982 (both of which were performed under identical conditions) was calculated to determine the percentage of loss of bone height over the last 10 years and the mean value for each disease type was translated into actual loss of bone height and expressed in millimeters.

Clinical examination of each patient included testing for tooth mobility, periodontal pocketing and gingival recession ${ }^{15}$ on the maxillary central incisors and an assessment of the general periodontal condition including the extent of calculus deposits. Statistical evaluation was performed using the Student's $t$-test. ${ }^{16}$

\section{Results}

Table 1 summarizes the loss of alveolar bone height (alveolar bone loss) expressed as a percentage observed for each patient, and also compares similar data observed on the same patients in $1978^{7}$ and $1982 .^{9}$ A 59-year-old lepromatous patient had his incisors missing, precluding measurements. However, the corresponding data from 1978 and 
Table 1. Maxillary anterior alveolar bone loss and periodontal measurements

\begin{tabular}{|c|c|c|c|c|c|c|c|c|}
\hline \multirow[b]{2}{*}{ Disease Type } & \multicolumn{2}{|c|}{ Age of patient } & \multicolumn{2}{|c|}{$\begin{array}{l}\text { Percent alveolar } \\
\text { bone loss* }\end{array}$} & \multirow[b]{2}{*}{ Mobil } & \multicolumn{2}{|c|}{$\begin{array}{c}\text { Maximal } \\
\text { periodontal } \\
\text { measurement } f\end{array}$} & \multirow[b]{2}{*}{ Calculus } \\
\hline & (1992) & 1978 & 1982 & 1992 & & Pocket & Recession & \\
\hline \multirow[t]{5}{*}{ Lepromatous } & 59 & 37 & 37 & - & - & - & - & - \\
\hline & 64 & 22 & 22 & 24 & 0 & 1 & 4 & 1 \\
\hline & 68 & 32 & 36 & 36 & 0 & 2 & 3 & 2 \\
\hline & 69 & 26 & 30 & 29 & 1 & 4 & 0 & 3 \\
\hline & 70 & 23 & 27 & 37 & 1 & 2 & 3 & 2 \\
\hline \multirow[t]{5}{*}{ Borderline } & 46 & 10 & 10 & 19 & 0 & 3 & 0 & 3 \\
\hline & 53 & 20 & 25 & 31 & 1 & 2 & 0 & 3 \\
\hline & 54 & 13 & 17 & 22 & 0 & 2 & 0 & 2 \\
\hline & 58 & 17 & 17 & 16 & 0 & 3 & 2 & 2 \\
\hline & 64 & 17 & 19 & 22 & 1 & 3 & 0 & 2 \\
\hline \multirow[t]{3}{*}{ Tuberculoid } & 58 & 14 & 14 & 15 & 0 & 4 & 0 & 3 \\
\hline & 62 & 29 & 29 & 33 & 1 & 2 & 4 & 2 \\
\hline & 66 & 23 & 25 & 30 & 1 & 2 & 4 & 2 \\
\hline
\end{tabular}

* Values rounded to nearest whole number.

$\ddagger$ Largest periodontal measurements of maxillary central incisors: mobility $=0,1,2$, or 3 ; periodontal pocketing and recission in $\mathrm{mm}$; calculus $=1$ (slight), 2 (moderate) or 3 (heavy).

1982 for this patient are included for comparative purposes. He also had the greatest bone loss, but had no net loss of bone over the initial 4-year period. The mean alveolar bone loss observed for the lepromatous patients in the present study $(31.5 \pm 5.3 \%)$ is significantly greater $(p<0.05)$ than that seen in patients with borderline leprosy $(22 \pm 5.0 \%)$ but not for those with tuberculoid leprosy $(26 \pm 7 \cdot 8 \%)$. This observation also holds true for similar data recorded in 1978 and 1982. A qualitative assessment also showed that, in general, the loss in alveolar bone height is either static or minimal, considering that it extends over a decade. In order to assess this more accurately, the difference in the amount of alveolar bone lost in each disease type was calculated over the period of study. These data were then compared with those obtained for the same patient group over the earlier 4-year period (1978-82) and summarized in Table 2. From the combined data in Table 2, it is possible to estimate the percentage bone loss over a period of approximately 14 years. The loss in alveolar bone height over this period was $5 \cdot 2 \%$ (lepromatous), $6 \cdot 6 \%$ (borderline) and $4 \cdot 4 \%$ (tuberculoid). An interesting observation in Table 2 is, despite lepromatous patients as a whole registering the greatest total loss in alveolar bone height (from the onset of our study in 1978), the rate of bone loss is the lowest $(2 \cdot 8 \%)$ when compared to patients with tuberculoid $(3 \cdot 3 \%)$ or borderline $(4.4 \%)$ leprosy. The presumed loss in bone height over the 10 -year period was also calculated based on an assumed mean root length of $13 \mathrm{~mm}$ for central incisors plus $3 \mathrm{~mm}$ being the height of the curvature of the cervical line. ${ }^{17}$ The rate of loss of alveolar bone height was calculated at $0.06 \mathrm{~mm}$ per year for lepromatous or tuberculoid leprosy and $0.08 \mathrm{~mm}$ per year for borderline leprosy.

In general, the periodontal status (Table 1) in these patients was not different from 
Table 2. The rate of alveolar bone loss in the anterior maxilla by disease type

\begin{tabular}{lccccc}
\hline & \multicolumn{3}{c}{ Mean loss of alveolar bone } \\
\cline { 2 - 3 } & \multicolumn{2}{c}{ Period: 4 years } & & \multicolumn{2}{c}{ Period: 10 years } \\
\cline { 2 - 3 } \cline { 5 - 6 } Disease Type & $\%$ & $\mathrm{~mm}^{*}$ & & $\%$ & $\mathrm{~mm}^{*}$ \\
\hline $\begin{array}{l}\text { Lepromatous } \\
\text { Borderline }\end{array}$ & 2.4 & 0.38 & & 2.8 & 0.45 \\
Tuberculoid & 2.2 & 0.35 & & 4.4 & 0.70 \\
& 2.1 & 0.34 & & 3.3 & 0.53 \\
\hline
\end{tabular}

* Based on a mean alveolar bone height of $16 \mathrm{~mm}$ adjacent to the proximal and distal surfaces of maxillary central incisors (see text for details).

our observations in 1982. Maxillary central incisors had little or no mobility and other parameters of periodontal inflammation were of slight to moderate magnitude. The most severe were calculus deposits around the maxillary central incisors which were moderate to heavy in all patients except a 64-year-old lepromatous male who had no visible deposits. Gingival recession up to $4 \mathrm{~mm}$ around the maxillary incisors was seen in lepromatous and tuberculoid patients. Periodontal pocketing greater than $3 \mathrm{~mm}$ was found in only 2 patients.

\section{Discussion}

These data show that continuity of treatment has a beneficial effect on maxillary alveolar bone loss in patients with leprosy and suggest that it may also reduce other skeletal deformities. It has been shown that alveolar bone resorption in the anterior maxilla is a characteristic skeletal deformity of leprosy $y^{2,4,5}$ and that it is greatest in untreated patients with lepromatous disease, ${ }^{7,8,9,12}$ who by the 4 th decade have the same alveolar bone loss as patients in Malaysia without leprosy who are in their 6th decade. ${ }^{7,18}$ While alveolar bone loss around the maxillary incisors was initially greater in patients with lepromatous leprosy when compared with the other 2 types, the rate of loss in the present study was lowest in this group (Table 2). Patients with borderline leprosy recorded the highest rate of bone loss over the same period, about $30 \%$ greater than patients with lepromatous or tuberculoid leprosy. Thus our data suggest that successful treatment of the disease greatly reduces alveolar bone loss in patients with leprosy. These observations support our earlier findings ${ }^{9}$ and infer that the longer the duration of untreated disease, the greater the tendency for alveolar bone loss in the anterior maxilla. ${ }^{12}$

Upon closer examination, it was noted that the rate of loss in these patients with leprosy with poor oral hygiene is similar to that in younger patients without leprosy with good oral hygiene. ${ }^{10,11}$ Loe et al. ${ }^{10,11}$ studied more than 1000 subjects younger than 40 years old in Norway and Sri Lanka over 6 years to assess periodontal status and loss of alveolar bone. The rate of attachment loss (which varies directly with loss of alveolar 
bone support over long periods) was $0.08 \mathrm{~mm}$ and $0.29 \mathrm{~mm}$ per year for Norwegians and Sri Lankans, respectively. The difference between the 2 groups was attributed to the relative oral health status. The Norwegians had much less plaque and gingival inflammation and better oral hygiene than the Sri Lankans. The rate of alveolar bone loss seen in the present study is similar to that of the Norwegians but the oral hygiene in our leprosy patients is poor (similar to the Sri Lankans). The incidence of calculus and gingival inflammation in these patients with leprosy (Table 1) is similar to those in agematched Malaysians without leprosy but the rate of alveolar bone loss in treated patients with leprosy is considerably less. ${ }^{9,12}$ Thus, the correlation between the reduced rate of bone loss and poor oral hygiene in the patients in our study is a paradox since plaque accumulations and periodontal disease are directly related to alveolar bone destruction in populations without leprosy. ${ }^{10,11,13,15,19}$

What then is the reason for the initial susceptibility of patients with lepromatous leprosy to maxillary anterior bone loss? The suggestion that bone loss is directly attributable to some local effect of Mycobacterium leprae concentrations in the nasal mucosa is appealing and conceptually simple. A recent observation suggests that bone loss could be preceded by erythema nodosum leprosum (ENL) ${ }^{20}$ It has been suggested that the immunologically mediated destructive ulceration arising from severe ENL reactions could initiate or aggravate bone destruction in the premaxilla, ${ }^{21}$ or other bones. $^{22}$ Initiation and continuity of treatment may protect alveolar bone from this destructive influence in patients with leprosy. It is also possible that the specific immune derangements that make patients susceptible to leprosy in the first place may also protect them from alveolar bone loss associated with periodontal disease. ${ }^{12}$ These possibilities need to be examined.

\section{Acknowledgments}

This work was supported by the University of Malaya (grant No. 135/77), the Heiser Program for Research in Leprosy, and Colgate-Palmolive/Malaysia.

We thank the director and staff of the National Leprosy Control Centre, Malaysia for their support. Our special thanks go to Mr Chiew Hock Koon for his chairside assistance, the patients who participated in the study and Mr Zulhisham, Professional Relations Manager of Colgate-Palmolive Co.

\section{References}

${ }^{1}$ Lechat MF. Bone lesions in leprosy. Int J Lepr, 1962; 30: 125.

2 Moller-Christensen V. Ten lepers from Naestved in Denmark. A study of skeletons from a medieval leper hospital. Copenhagen. Danish Science Press Ltd., 1953. p. 160.

${ }^{3}$ Paterson DE. Bone changes in leprosy: their incidence, progress, prevention and arrest. Int J Lepr, 1961; 29: 393.

${ }^{4}$ Moller-Christensen V, Bakke SN, Melsom RS, Waaler E. Changes in the anterior nasal spine and the alveolar process of the maxillary bone. Int J Lepr, 1952; 20: 335.

5 Michman J, Sagher F. Change in the anterior nasal spine and the alveolar process of the maxillary bone in leprosy. Int J Lepr, 1957; 25: 217.

6 Southam JC, Venkataraman BK. Oral manifestations of leprosy. Br J Oral Surg, 1973; $10: 272$.

7 Subramaniam K, Marks SC. Alveolar bone loss in leprosy. Lepr Rev, 1978; 49: 287.

${ }^{8}$ Marks SC Jr, Subramaniam K. The cellular basis for alveolar bone loss in leprosy. Lepr Rev, 1978; $49: 297$. 
9 Subramaniam K, Marks SC, Nah SH. The rate of loss of maxillary anterior alveolar bone height in patients with leprosy. Lepr Rev, 1983; 54: 119.

10 Loe H, Anerud A, Boysen H, Smith M. The natural history of periodontal disease in man: the rate of periodontal destruction before 40 years of age. J Period, 1978; 49: 607.

11 Anerud A, Loe H, Boysen H, Smith M. The natural history of periodontal disease in man: changes in gingival health and oral hygiene before 40 years of age. J Periodontal Res, 1979; 14: 526.

$12 \mathrm{Nah}$ SH, Marks SC, Subramaniam K. Relationship between the loss of maxillary anterior alveolar bone and the duration of untreated lepromatous leprosy in Malaysia. Lepr Rev, 1985; 56: 51.

13 Schei O, Waerhaug J, Lovdal A, Arno A. Alveolar bone loss as related to oral hygiene and age. $J$ Clin Period, 1959; 30: 7.

14 Lang NP, Hill RW. Radiographs in periodontics. J Clin Period, 1977; 4: 16.

15 Rateitschak KH, Rateitschak EM, Wolf HF, Hassell TM. In: Color Atlas of Dental Medicine, Vol. 1, Periodontology. 2nd Ed. Rateitschak KH (ed). New York, Thieme, 1989.

16 Armitage P. Statistical Methods in Medical Research, New York, J. Wiley, 1971, p. 104.

17 Wheeler RC. Dental Anatomy: Physiology and Occlusion. Philadelphia, W. B. Saunders, 1974. p.136.

18 Subramaniam K. Marks SC Jr, Nair S, Ho KH. Profile of periodontal disease in an urban adult population in Malaysia. J Malaysian Soc Health, 1985; 5: 97.

19 Socransky SS, Haffajee AD, Goodson JM, Lindhe J. New concepts of destructive periodontal disease. J Clin Periodontol, 1984; 11: 21.

20 Scheepers A. Erythema nodosum leprosum: a possible cause of oral destruction in leprosy. Int J Lepr, 1992; 60: 641 .

21 Rendall JR, McDougall AC. Reddening of the upper central incisors associated with periapical granuloma in lepromatous leprosy. Br J Oral Surg, 1976; 13: 271.

22 Moller-Christensen V. Bone Changes in Leprosy. Copenhagen, Munksgaard, 1961, pp. 14-15. 